\title{
A Retrospective Longitudinal Analysis of Risk Factors, Treatment Outcomes and Imaging Parameters of Ventricular Collapse in Idiopathic Intracranial Hypertension
}

\section{Riccardo Serra ( $\nabla$ ric.serra91@yahoo.com )}

University of Maryland School of Medicine https://orcid.org/0000-0002-1975-393X

\section{Smruti Mahapatra}

Johns Hopkins University - Homewood Campus: Johns Hopkins University

\section{Sakibul Huq}

Johns Hopkins Medical Institutions: Johns Hopkins Medicine

\section{Michael Meggyesy}

Johns Hopkins University School of Medicine

Noah Leviton Gorelick

Johns Hopkins University School of Medicine

Lacie Manthripragada

Johns Hopkins University School of Medicine

Abhay Moghekar

Johns Hopkins University School of Medicine

Mark Gregory Luciano

Johns Hopkins University School of Medicine

\section{Research}

Keywords: Ventricular Collapse, Idiopathic Intracranial Hypertension, Pseudotumor Cerebri, Slit-Ventricle Syndrome

Posted Date: December 16th, 2020

DOl: https://doi.org/10.21203/rs.3.rs-127188/v1

License: (9) (1) This work is licensed under a Creative Commons Attribution 4.0 International License. Read Full License 


\section{Abstract}

\section{Objective}

Ventricular collapse is a prevalent yet poorly understood complication of ventriculo-peritoneal shunting (VPS) in patients with idiopathic intracranial hypertension (IIH). By identifying and describing the risk factors of ventricular collapse (VC), this study aims to characterize the clinical progression, etiopathogenesis and treatment of $\mathrm{IH}$ and its complications. The relationships between ventricular size, symptoms and treatments were also assessed longitudinally with ventricular segmentation on MRI/CT imaging, and correlated with other risk factors of IIH and VC.

\section{Methods}

We retrospectively reviewed records of 147 patients who underwent VPS for IIH at our Institution, and identified 73 shunt-naïve subjects included in the final analysis. Manual segmentation of CT/MRI scans was performed longitudinally at each clinical stage (baseline, post-shunting, post-collapse and after each intervention). Variables collected included valve type and opening-pressure, shunt revisions, use of antisiphoning devices (ASD), comorbidities, venous sinus hypoplasia/stenosis and stenting, and general demographics. Linear univariate regression models were used to determine the association between individual risk factors and VC, and to quantitatively assess the effect of treatment. Two multivariate models were also tested, including Pre-Shunting and Post-Shunting variables, to quantify their association with VC.

\section{Results}

Of $73 \mathrm{IIH}$ patients with new shunts, 32 experienced collapse (uni- or bilateral, $26.5 \%$ of the total). In shuntnaïve patients, collapse was associated with pre-shunting ( $r \mathrm{ho}=-0.36 ; \mathrm{p}=0.001)$ and post-shunting ventricular size ( $r h o=0.62 ; p=0.0002)$. Both collapse and ventricular area were correlated with shuntrelated symptoms at 6 months (rho $=-0.29 ; p=0.01$ ). Shunt adjustment, addition of ASDs, and valve replacement proved to be the most effective strategies to re-expand the ventricles and reduce symptoms. Nonetheless, a significant fraction of patients remained symptomatic after multiple treatments, suggesting a complex and multifactorial etiology for VC. On univariate analysis, catheter revisions were more common in the $\mathrm{VC}$ group, while the multivariate model with Post-Shunting risk factors proved to be significantly associated with VC.

\section{Conclusions}


In newly VP-shunted IIH patients, small ventricular size predisposed to collapse and headaches, while higher valve OPs and ASDs may reduce the risk of collapse and promote symptomatic improvement. Within the restraints of a retrospective analysis, this study is the first to analyze the risk factors of VC in $\mathrm{IIH}$ patients, longitudinally integrating the clinical progression with ventricular imaging. Further prospective studies are warranted to better understand the etiopathogenesis and clinical progression of collapse.

\section{Background}

Idiopathic intracranial hypertension $(\mathrm{IIH})$ is a poorly understood disease defined by increased intracranial pressure (ICP) in absence of other known causes and normal CSF${ }^{1}$. The typical presentation includes headaches, papilledema, transient visual obscurations and blindness ${ }^{2}$, as well as abducens nerve palsy, tinnitus, and mood disturbance ${ }^{2}$. Acetazolamide and topiramate have been mainstays of treatment ${ }^{1}$, though over the past decades CSF diversion surgery (i.e. ventriculo-peritoneal shunting (VPS)) has grown in popularity, particularly in patients with rapid vision deterioration and persistent/worsening headaches ${ }^{3-7}$. While VPS is efficacious in reducing symptoms and preserving vision, treatment frequently fails or gives rise to major complications, such as headaches, confusion, changes in vision and dizziness ${ }^{8}$.

One of the most troublesome complications of CSF diversion in IIH is ventricular collapse $(\mathrm{VC})^{8}$. While the etiology is unknown, it is thought that the slit-like appearance of ventricles in IIH and elevated ICP may predispose them to collapse upon VPS ${ }^{9-11}$. Uni- or bilateral VC has been described as part of the SlitVentricle Syndrome (SVS) when diagnosed in association with headaches and slow valve-refill ${ }^{12-14}$. Interestingly, little is known of the similarities between VC in IIH and some features of SVS, limiting our understanding of shunt-related symptomatology. Despite seeing a general improvement after shunting, these patients worsen progressively in the months post-surgery as a consequence of overdrainage and ventricular collapse, with significant costs ${ }^{14,15}$. Intermittent and supraphysiologic shunting, small ventricles and raised ICP, as well as depression, obesity and anxiety have all been reported as possible explanations for headaches, but their impact has never been fully understood and characterized ${ }^{14}$.

The primary objective of this study was to determine the incidence and risk factors of VC in shunted patients with $\mathrm{IIH}$, to study its clinical progression in parallel with the evolution of ventricular size and shape, and describe potential therapeutic strategies to address its symptomatology. Furthermore, we analyzed the effect of individual risk factors (obesity, venous sinus stenosis/stenting, hardware used) on ventricular collapse and size, and correlated them with the clinical presentation by means of uni- and multivariate statistical models. Manual segmentation of CT/MRI scans was obtained to calculate the baseline and post-shunting/collapse/re-expansion size of lateral ventricles. Shunt valve characteristics and a longitudinal evaluation of the clinical history and treatment outcomes was then performed in a 
retrospective fashion. To our knowledge, this is the first longitudinal retrospective study to assess the risk factors, clinical presentation and treatment strategy of $\mathrm{VC}$ in IIH, integrating clinical data (headaches and other symptoms) with quantifiable and reproducible measurements of both ventricular collapse (present vs. absent) and ventricular size on imaging.

\section{Methods}

\section{Study Design, Inclusion Criteria and Patient Population}

After obtaining approval from the Institutional Review Board, we performed a retrospective analysis of patients diagnosed with IIH that received VPS at our and/or other institutions. Inclusion criteria for this study: 1) Patients presenting with a diagnosis of IIH and treated for the first time with a VPS at our Institution; 2) VPS implantation between September 2015 and September 2018; 2) minimum follow-up of 1 year post-VPS.

\section{Variables collected}

We retrospectively reviewed the clinical records in Epic (Epic, Verona, WI, USA) and collected demographic data, diagnosis, type/settings of shunt/ASD, dates/types of operations, intraoperative findings, occurrence of shunt failure/revision, treatment modalities, and outcomes at multiple time-points (immediately and at 2/6 months post-operatively). Opening pressures (OPs) on lumbar puncture (LP) before shunting, papilledema, ICP monitoring, CSF leaks were also collected. We then identified patients presenting with symptoms and radiological signs of VC; followed their clinical course and reviewed therapies, outcomes, and radiologic response. Venous stenosis, stenting, and venous pressures were recorded. Patients with VPS implanted at other institutions were excluded from the final analysis.

\section{Imaging Evaluation}

$\mathrm{CT} / \mathrm{MRI}$ scans were reviewed to identify patients with radiologic VC. Ventricular collapse - VC was defined as absence of CSF around the catheter tip in the shunted ventricle and a normal or negligible volume on the contralateral ventricle (Fig. 1a-h). Preoperative, postoperative, post-VC, and post-treatment scans were also collected for each subject. We then performed manual segmentation and calculated the lateral ventricular area at the point of maximum width for each timepoint (Fig. 1a-h). Importantly, both the occurrence of $\mathrm{VC}$ and the radiologic changes in ventricular size were analyzed in relation to the clinical presentation, symptoms, valve type/setting and intervention. Baseline and post-shunting volumes were analyzed as individual risk factors for ventricular collapse. CARESTREAM Vue PACS ${ }^{\circledR}$ software (Carestream, Rochester, NY, USA) was used for image collection, segmentation and analysis. Image segmentation was performed in a blinded fashion by a third investigator, and patient outcomes were not disclosed at the time of analysis.

\section{Statistical Analysis}


Collected data were organized in Microsoft Excel (Microsoft Corp., Seattle, Washington, USA). Statistical analysis was performed with RStudio (Boston, MA, USA) and GraphPad Prism ${ }^{\circledR}$ (Version 8.1.0, San Diego, CA, USA) by a third blinded assessor. Pearson and Spearman's tests were applied for assessing correlations. Univariate analyses were performed with Fisher's exact test, unpaired t-test and MannWhitney U-test. Logistic and linear regression analyses were performed to assess associations between risk factors, ventricular areas and VC. Univariate and multivariate models were created for all variables. Logistic and linear regression analyses were performed on the data collected from newly-shunted IIH patients and analyzed with two-way Anova. P-values $<0.05$ were considered statistically significant.

\section{Results}

\section{Demographic and Clinical Data}

After an initial screening of 147 patients (Table 1; Fig. 2), seventy-three $(n=73)$ treatment-naïve subjects with $\mathrm{IH}$ were identified, including 62 females (86\%) and 11 males (14\%) (Table 2; Fig. 2). Average age among treatment-naïve patients was 39.1 years $(S D \pm 2.4)$, mean $B M I 38.3 \mathrm{~kg} / \mathrm{m}^{2}(\mathrm{SD} \pm 9.2), 26$ were previous/current tobacco smokers $(26 / 73,35 \%)$ (Table 2$)$, and mean follow-up from initial shunt implantation (range 12-49) was 28 months. Uni- or bilateral VC on imaging occurred in $32 \mathrm{IIH}$ patients out of $73(44 \%)$ (Table 2$)$. 
Table 1

Cohort Demographics and Univariate Analyses for Individual Risk Factors of Collapse. General characteristics of a cohort of 147 patients diagnosed with IIH and shunted with ventriculo-peritoneal shunts at our institution and/or at other institutions before. Chi-square test $(\dagger)$ and Unpaired t-test were used for univariate analysis. Significant $p$-values are bolded.

\begin{tabular}{|c|c|c|c|c|}
\hline $\begin{array}{l}\text { IIH patients with VP } \\
\text { Shunts }\end{array}$ & $\begin{array}{l}\text { All Patients } \\
\mathrm{N}=147\end{array}$ & $\begin{array}{l}\text { Patent } \\
\text { Ventricles } \\
\mathrm{N}=96(65 \%)\end{array}$ & $\begin{array}{l}\text { Collapsed } \\
\text { Ventricles } \\
\mathrm{N}=51(35 \%)\end{array}$ & $\begin{array}{l}\text { Univariate } \\
\text { Analysis } \\
\text { p-value }\end{array}$ \\
\hline Previously Shunted & 74 & $55(74 \%)$ & $19(26 \%)$ & $0.02+$ \\
\hline Newly Shunted & 73 & $41(56 \%)$ & $32(44 \%)$ & \\
\hline Age (y) & 40 & 42 & 39 & 0.58 \\
\hline Previously Shunted & 41 & 41.4 & 41.5 & 0.21 \\
\hline Newly Shunted & 39.2 & 38.3 & 40.4 & 0.43 \\
\hline Gender & 147 & 96 & 51 & $0.40 \dagger$ \\
\hline Previously Shunted & 74 & 47 & 27 & $0.99+$ \\
\hline Female & 70 & 44 & 26 & $0.99+$ \\
\hline Male & 4 & 3 & 1 & \\
\hline Newly Shunted & 73 & 41 & 32 & \\
\hline Female & 62 & 35 & 27 & \\
\hline Male & 11 & 6 & 5 & \\
\hline BMI (SD; kg/m²) & $38.3 \pm 9.2$ & $37.7 \pm 8.7$ & $38.8 \pm 9.9$ & 0.54 \\
\hline Previously Shunted & $36.8 \pm 9.2$ & $35.3 \pm 8.2$ & $39.2 \pm 10.3$ & 0.08 \\
\hline Newly Shunted & $39.7 \pm 9$ & $40.7 \pm 8.3$ & $38.5 \pm 9.8$ & 0.30 \\
\hline p-value & 0.05 & 0.003 & 0.79 & \\
\hline \multirow{2}{*}{$\begin{array}{l}\text { Number of Valves } \\
\text { (Average) }\end{array}$} & \multirow{2}{*}{$\begin{array}{l}250 \\
(1.71 / p t .)\end{array}$} & 146 (1.69/pt.) & 104 (1.73/pt.) & 0.57 \\
\hline & & 99 (2.3/pt.) & 66 (2.44/pt.) & 0.31 \\
\hline \multirow{3}{*}{$\begin{array}{l}\text { Previously Shunted } \\
\text { Newly Shunted } \\
\text { p-value }\end{array}$} & $\begin{array}{l}165 \\
(2.3 / \text { pt. })\end{array}$ & 47 (1.1/pt.) & 38 (1.18/pt.) & \\
\hline & 85 (1.2/pt.) & $<0.001$ & $<0.001$ & \\
\hline & $<0.001$ & & & \\
\hline
\end{tabular}


Table 2

Newly-shunted IIH Patients, Risk Factors and Univariate Analyses for Ventricular Collapse. Demographic and clinical data of $73 \mathrm{IHH}$ patients shunted for the first time at our institution. Right column - univariate analyses calculated with Fisher's exact test, paired t-test, Mann-Whitney $U$ test and Chi-square test $(\dagger)$.

Significant $p$-values are bolded.

\begin{tabular}{|c|c|c|c|}
\hline $\begin{array}{l}\text { IlH patients with New VP } \\
\text { Shunts }\end{array}$ & $\begin{array}{l}\text { All } \\
\text { Patients } n \\
=73\end{array}$ & $\begin{array}{l}\text { Patent Ventricles } \\
n=41(56 \%)\end{array}$ & $\begin{array}{l}\text { Collapsed Ventricles } \\
n=32(44 \%)\end{array}$ \\
\hline
\end{tabular}

\section{PRE-SHUNT VARIABLES}

$\begin{array}{lllll}\text { Age }(\mathrm{y}) & 39.1 \pm 2.4 & 38.3 & 40.4 & 0.43 \\ \text { Gender } & 62(85 \%) & 35(56 \%) & 27(84 \%) & 0.99 \\ \text { Female } & 11(15 \%) & 6(44 \%) & 5(16 \%) & \end{array}$

Male

BMI (SD; $\left.\mathrm{kg} / \mathrm{m}^{2}\right)$

$39.7 \pm 9$

$40.7 \pm 8.3$

$38.5 \pm 9.8$

0.30

Follow-Up Period

6-49

6-48

8-49

0.47

(range; months)

Smoking (current and former)

$26(35 \%) \quad 14(54 \%)$

$12(46 \%)$

0.99

Bilateral Sinus Stenosis

$17(23 \%)$

$11(27 \%)$

$6(18 \%)$

0.57

Opening Pressure at

Baseline (SD)

34.1

(12.2)

35.1 (11.5)

$32.6(13.2)$

0.42

Sinus Stenting Before

Shunting

CSF Leak Before

Shunting

Medical Tx*

$4(80 \%)$

$3(100 \%)$

$1(50 \%)$

ICPm

$8(100 \%)$

$2(100 \%)$

$6(100 \%)$

\section{POST-SHUNT VARIABLES}

\begin{tabular}{lllll}
$\begin{array}{l}\text { Sinus Stenting After } \\
\text { Shunting }\end{array}$ & $1(20 \%)$ & $0(0 \%)$ & $1(50 \%)$ & 0.99 \\
\hline CSF Leak After Shunting & $0(0 \%)$ & $0(0 \%)$ & $0(0 \%)$ & 0.17 \\
\hline $\begin{array}{l}\text { Improved Headaches at 2 } \\
\text { mos }\end{array}$ & $57 \%$ & $30(73 \%)$ & $12(68 \%)$ & $\mathbf{0 . 0 2 +}$ \\
\hline $\begin{array}{l}\text { Improved Headaches at 6 } \\
\text { mos }\end{array}$ & $41 \%$ & $22(53 \%)$ & $8(25 \%)$ &
\end{tabular}




\begin{tabular}{|c|c|c|c|c|}
\hline $\begin{array}{l}\text { IlH patients with New VP } \\
\text { Shunts }\end{array}$ & $\begin{array}{l}\text { All } \\
\text { Patients } n \\
=73\end{array}$ & $\begin{array}{l}\text { Patent Ventricles } \\
n=41 \text { (56\%) }\end{array}$ & $\begin{array}{l}\text { Collapsed Ventricles } \\
n=32(44 \%)\end{array}$ & $\begin{array}{l}\text { Univariate } \\
\text { Analysis } \\
p \text {-value }\end{array}$ \\
\hline Headaches at 6 mos & $31 \%$ & $9(22 \%)$ & $14(43 \%)$ & \\
\hline Impaired Vision at 6 mos & $1.5 \%$ & $0(0 \%)$ & $1(3 \%)$ & \\
\hline $\begin{array}{l}\text { Dizziness-Instability at } 6 \\
\text { mos }\end{array}$ & $3 \%$ & $1(2.5 \%)$ & $1(3 \%)$ & \\
\hline $\begin{array}{l}\text { Headaches and Impaired } \\
\text { Vision at } 6 \text { mos }\end{array}$ & $7 \%$ & $1(2.5 \%)$ & $4(12.5 \%)$ & \\
\hline Post-Shunt Scans & 3.58 & 3.58 & 3.59 & 0.99 \\
\hline Number of Valves & $1.2 / \mathrm{pt}$. & 45 (1.1/pt.) & $38(1.18 / p t)$. & 0.31 \\
\hline Replaced Valves & & $4 / 41(10 \%)$ & $6 / 32(18 \%)$ & \\
\hline \multirow{2}{*}{$\begin{array}{l}\text { Number of Catheter } \\
\text { Revisions }\end{array}$} & \multirow[t]{3}{*}{$0.7 / \mathrm{pt}$} & $4(10 \%)$ & $15(47 \%)$ & 0.004 \\
\hline & & $3 / 41$ & $6 / 32$ & \\
\hline Distal Catheter & & $1 / 41$ & $9 / 32$ & \\
\hline
\end{tabular}

\section{Risk Factors for Ventricular Collapse}

We performed univariate and multivariate analyses on pre- and post-shunting CT/MRI scans to individuate risk-factors linked to VC (Table 3; Supplementary Table 1). On univariate analysis, VC was associated with both pre-operative ventricular size (rho $=-0.36 ; p=0.001)$ and post-operative ventricular size (rho $=-0.62 ; p<0.001$ ) (Table 3). Right and left ventricular size separately, before and after shunting, were also correlated with the occurrence of VC (Table 3). A small non-significant association was found between VC and the difference in ventricular size before and after VPS (rho $=0.19, p=0.09$; Table 3 ). 
Table 3

Effect of Individual Risk Factors on Ventricular Collapse upon Shunting. Logistic and linear regression analyses. Association of pre-shunt, post-shunt and pre-/post-shunt difference in right, left and total ventricular area with risk of ventricular collapse. Significant $p$-values are bolded.

\begin{tabular}{|ll|}
\hline Area measurements & Ventricular Collapse \\
\hline Pre-Shunt Total Ventricular Area & $\mathbf{p}=\mathbf{0 . 0 0 1}$ \\
'ho $=-0.36$
\end{tabular}

Importantly, factors thought to play a role in IIH and VC, such as age, gender, BMI, sinus stenosis, OP, and tobacco use were not significantly associated with ventricular collapse on univariate or multivariate analysis. 
Table 4

Longitudinal Ventricular Changes in Size at Baseline, Post-Shunting, Post-Collapse and Post-Treatment. Ventricular area measurements of $73 \mathrm{IIH}$ patients shunted for the first time at our institution. Right, left and total areas are shown for each timepoint, and patent vs. collapsed ventricles areas were analyzed with paired t-test. Significant $p$-values are bolded. The effect of shunt adjustment, proSA ${ }^{\circledR}$ addition and valve replacement was also analyzed and compared to pre-treatment ventricular area. $†$ comparison between post-collapse and post-treatment ventricular areas in patients treated with shunt adjustment,

ASD addition and valve replacement.

\begin{tabular}{|c|c|c|c|c|}
\hline $\begin{array}{l}\text { IIH patients with New VP } \\
\text { Shunts }\end{array}$ & $\begin{array}{l}\text { All } \\
\text { Patients } n \\
=73\end{array}$ & $\begin{array}{l}\text { Patent Ventricles } \\
n=41(56 \%)\end{array}$ & $\begin{array}{l}\text { Collapsed Ventricles } \\
n=32(44 \%)\end{array}$ & $\begin{array}{l}\text { Univariate } \\
\text { Analysis } \\
\text { p-value }\end{array}$ \\
\hline Pre-Shunting Area & $10.55 \mathrm{~cm}^{2}$ & $12.56 \mathrm{~cm}^{2}$ & $8.43 \mathrm{~cm}^{2}$ & 0.002 \\
\hline $\begin{array}{l}\text { Right Ventricle } \\
\text { (ipsilateral) }\end{array}$ & $5.22 \mathrm{~cm}^{2}$ & $5.99 \mathrm{~cm}^{2}$ & $4.39 \mathrm{~cm}^{2}$ & \multirow{2}{*}{$\begin{array}{l}0.02 \\
0.001\end{array}$} \\
\hline Left Ventricle & $5.32 \mathrm{~cm}^{2}$ & $6.56 \mathrm{~cm}^{2}$ & $4.03 \mathrm{~cm}^{2}$ & \\
\hline Post-Shunting Area & $6.32 \mathrm{~cm}^{2 \star}$ & $11.09 \mathrm{~cm}^{2}$ & $5.28 \mathrm{~cm}^{2 \star \star}$ & \multirow{4}{*}{$\begin{array}{l}<0.001 \\
<0.001 \\
<0.001\end{array}$} \\
\hline $\begin{array}{l}\text { Right Ventricle } \\
\text { (ipsilateral) }\end{array}$ & $3.64 \mathrm{~cm}^{2}$ & $5.58 \mathrm{~cm}^{2}$ & $2.09 \mathrm{~cm}^{2}$ & \\
\hline Left Ventricle & $4.23 \mathrm{~cm}^{2}$ & $5.51 \mathrm{~cm}^{2}$ & $3.18 \mathrm{~cm}^{2}$ & \\
\hline $\begin{array}{l}\text { p-value (pre- vs. post- } \\
\text { shunting) }\end{array}$ & 0.02 & 0.35 & $<0.001$ & \\
\hline Post-Collapse Area & $\mathrm{n} / \mathrm{a}$ & $\mathrm{n} / \mathrm{a}$ & $4.29 \mathrm{~cm}^{2}$ & \multirow[t]{4}{*}{$\mathrm{n} / \mathrm{a}$} \\
\hline $\begin{array}{l}\text { Right Ventricle } \\
\text { (ipsilateral) }\end{array}$ & & & $1.61 \mathrm{~cm}^{2}$ & \\
\hline Left Ventricle & & & $2.68 \mathrm{~cm}^{2}$ & \\
\hline $\begin{array}{l}\text { p-value (post-shunting vs. } \\
\text { post-collapse) }\end{array}$ & & & 0.07 & \\
\hline Post-Treatment Area & \multirow{8}{*}{$\begin{array}{l}n / a \\
n / a \\
n / a\end{array}$} & $\mathrm{n} / \mathrm{a}$ & $6.29 \mathrm{~cm}^{2 \star}$ & \multirow{8}{*}{$\begin{array}{l}\mathrm{n} / \mathrm{a} \\
\mathrm{n} / \mathrm{a} \\
0.09+ \\
0.004 \dagger \\
\mathrm{n} / \mathrm{a}\end{array}$} \\
\hline $\begin{array}{l}\text { Right Ventricle } \\
\text { (ipsilateral) }\end{array}$ & & $\mathrm{n} / \mathrm{a}$ & $3.66 \mathrm{~cm}^{2}$ & \\
\hline Left Ventricle & & $n / a$ & $2.69 \mathrm{~cm}^{2}$ & \\
\hline $\begin{array}{l}\text { p-value (post-collapse vs. } \\
\text { post-treatment) }\end{array}$ & & & 0.04 & \\
\hline By treatment: & & & $6.03 \mathrm{~cm}^{2}$ & \\
\hline Shunt Adjustment & & & $7.11 \mathrm{~cm}^{2}$ & \\
\hline $\operatorname{proSA}^{\circledR}$ & & & $13.32 \mathrm{~cm}^{2}$ & \\
\hline Valve Replacement & & & & \\
\hline
\end{tabular}




\begin{tabular}{|c|c|c|c|c|}
\hline $\begin{array}{l}\text { IIH patients with New VP } \\
\text { Shunts }\end{array}$ & $\begin{array}{l}\text { All } \\
\text { Patients } n \\
=73\end{array}$ & $\begin{array}{l}\text { Patent Ventricles } \\
n=41(56 \%)\end{array}$ & $\begin{array}{l}\text { Collapsed Ventricles } \\
n=32(44 \%)\end{array}$ & $\begin{array}{l}\text { Univariate } \\
\text { Analysis } \\
\text { p-value }\end{array}$ \\
\hline Area difference by side: & $-2.67 \mathrm{~cm}^{2}$ & $-1.46 \mathrm{~cm}^{2}$ & $-3.15 \mathrm{~cm}^{2}$ & 0.02 \\
\hline Pre/Post-Shunting Area & $-1.58 \mathrm{~cm}^{2}$ & $-0.57 \mathrm{~cm}^{2}$ & $-2.30 \mathrm{~cm}^{2}$ & $<0.001$ \\
\hline $\begin{array}{l}\text { Right Ventricle } \\
\text { (ipsilateral) }\end{array}$ & $-1.09 \mathrm{~cm}^{2}$ & $-1.18 \mathrm{~cm}^{2}$ & $-0.85 \mathrm{~cm}^{2}$ & 0.40 \\
\hline Left Ventricle & & & & \\
\hline
\end{tabular}

Two combinations of factors, either predisposing to VC or associated with shunting, were included in a multivariate analysis model (Table 5). The first model, a Pre-Shunting combination of Age, gender, OP on LP, bilateral sinus stenosis, BMI and pre-shunt total ventricular area, was significantly associated with ventricular collapse as a multivariate a regression model $\left(R^{2}=0.08, p=0.08\right)$, with pre-shunt total ventricular volume as the only significant individual factor $(p=0.008)$. The second model, including only Post-Shunting factors, such as post-shunt total ventricular volume, pre/post shunt area difference, and symptoms at 2 and 6 months, was significantly correlated with development of $V C\left(R^{2}=0.3, p<0.001\right)$ (Table 5).

Table 5

Multivariate regression analyses of Pre-Shunting and Post-Shunting Risk Factors for Ventricular Collapse. Model 1 - Predisposing Variables: association of age, gender, OP, bilateral sinus stenosis, $\mathrm{BMI}$ and preshunt total ventricular area with risk of ventricular collapse. Model 2Post-Shunt Determinants: association of pre-shunt total ventricular area, pre-/post-shunt area difference, symptoms at 2 and 6 months with risk of ventricular collapse. Significant $p$-values are bolded.

\begin{tabular}{|lll|}
\hline Independent Variables & Ventricular collapse & $\mathbf{p}$-value \\
\hline Age & 0.32 & $\mathbf{R}^{2}=\mathbf{0 . 0 8}$ \\
Gender & 0.46 & $\mathbf{p}=\mathbf{0 . 0 8}$ \\
Opening Pressure & 0.74 & \\
Bilateral Sinus Stenosis & 0.51 & \\
BMI & 0.12 & \\
Pre-Shunt Total Ventricular Area & $\mathbf{0 . 0 0 8}$ & $\mathbf{R}^{2}=\mathbf{0 . 3}$ \\
Post-Shunt Total Ventricular Area & $<\mathbf{0 . 0 0 1}$ & $\mathbf{p}<\mathbf{0 . 0 0 1}$ \\
Pre/Post-Shunt Area Difference & $\mathbf{0 . 0 2}$ & \\
Symptoms 2 months Post-Shunt & 0.82 & \\
Symptoms 6 months Post-Shunt & 0.14 & \\
\hline
\end{tabular}




\section{Symptoms and Radiologic Findings of Ventricular Collapse}

Thirty-two (32) subjects experienced VC after VPS, 15 of which developed bilateral collapse, while the remaining 17 had unilateral-right VC. Interestingly, VC was found to be significantly associated with headaches, decreased vision and vertigo at 6 months post-shunting (rho $=-0.29 ; p=0.01$; Supplementary Table 1), indicating a possible pathophysiological connection with these manifestations. Although common, this association was not always present in our cohort. In eight cases of VC (8/32, 25\%), a subjective improvement in headaches and other related manifestations was reported at 6 months postshunting. Resolution of headaches/vision impairment/vertigo, and the different combinations of these symptoms were considered in our analysis.

A statistically significant decrease in ventricular size post-VPS was also noticed among the subjects that subsequently developed VC, followed by another reduction in ventricular area that led to VC. Specifically, the total area shrank from $10.5 \mathrm{~cm}^{2}$ to $6.3 \mathrm{~cm}^{2}$ immediately post-VPS $(p=0.02$; Table 4$)$ versus from $12.5 \mathrm{~cm}^{2}$ to $11 \mathrm{~cm}^{2}$ in the patent ventricles cohort ( $p=0.35$; Table 4$)$ and from $8.4 \mathrm{~cm}^{2}$ to $5.2 \mathrm{~cm}^{2}$ in the VC group ( $<$ 0.001; Table 4). A further decrease was reported after radiologic VC was diagnosed on CT/MRI images, from $5.2 \mathrm{~cm}^{2}$ to $4.3 \mathrm{~cm}^{2}(p=0.08$; Table 4$)$.

Interestingly, symptoms are associated not only with collapse, but also more generally with smaller ventricular area ( $r h o=-0.32 ; p=0.006$ ). A larger difference in ventricular size between baseline and postVPS scans was also found in patients with VC, compared to patent ventricles. This finding was significant when total area (patent $-1.46 \mathrm{~cm}^{2}$ vs. collapsed $-3.15 \mathrm{~cm}^{2}, \mathrm{p}=0.02$; Table 4) and rightventricular area (patent $-0.57 \mathrm{~cm}^{2}$ vs. collapsed $-2.30 \mathrm{~cm}^{2}, \mathrm{p}<0.001$; Table 4) were analyzed, suggesting that $\mathrm{VC}$ is the result of a more pronounced decrease in volume in ventricles already smaller at baseline.

\section{Valve Type and Setting in Ventricular Collapse}

Valve type and setting were collected and analyzed in relation to the development of VC. Certas ${ }^{\circledR}$ Plus (Codman by Integra, Plainsboro, NJ) programmable valves without Siphonguard ${ }^{\circledR}$ (Codman by Integra) were implanted in 67 patients with newly-diagnosed $\mathrm{IH}$, while six patients were shunted with Certas ${ }^{\circledR}$ Plus with integrated Siphonguard ${ }^{\circledR}$. Certas ${ }^{\circledR}$ Plus valves were set to a resistance level of 4 in one patient, of 5 in 7 other cases, 6 in 64 patients, and 7 in one patient. These settings correspond to OPs of $11 \mathrm{cmH}_{2} \mathrm{O}(4)$, $14.5 \mathrm{cmH}_{2} \mathrm{O}(5), 18 \mathrm{cmH}_{2} \mathrm{O}(6)$ and $21.5 \mathrm{cmH}_{2} \mathrm{O}(7)$, respectively. Among patients with $\mathrm{VC}, 28$ had a Certas ${ }^{\circledR}$ Plus set to 6 , while only two patients had a setting of 5 , one of 7 and one of 4 ; one had a Certas ${ }^{\circledR}$ Plus with Siphonguard ${ }^{\circledR}$. Furthermore, 4 subjects in the patent group had their obstructed valve replaced, compared to $6 / 32$ in the VC group. Catheter revisions were also more common in the VC group with $15 / 32$ patients undergoing surgery for catheter blockage, compared to 4/41 among the remaining subjects (Table 2). 


\section{The Role of Opening Pressure and Postural Drainage in the Treatment of Ventricular Collapse}

After VC, symptomatic and radiologic outcomes were analyzed in relation to changes in valve OP, valve replacement, and ASD use (proSA ${ }^{\circledR}$ by Miethke). The first-line measure adopted after radiologic assessment of $\mathrm{VC}$ consisted of raising the programmable valve resistance, leading to an increase in the device OP and therefore prompting the lateral ventricles to expand (Fig. 3a, an example of ventricular reexpansion after valve adjustment). Right, left, and total ventricular size significantly increased after valve adjustment in ten patients $(10 / 32, \simeq 30 \%)$, while symptomatic improvement was reported in five subjects $(5 / 32,15 \%)$. Co-occurrence of symptomatic improvement with ventricular enlargement was found only in 5 patients $(5 / 32,15 \%)$. After failure of valve adjustment, the remaining patients underwent either the addition of an ASD, $(4 / 32,12.5 \%)$, valve replacement $(2 / 32,6 \%)$ or migraine therapy. Valve adjustment achieved an average increase in size of $1.75 \mathrm{~cm}^{2}(S D=3.08)$, while the addition of a proSA ${ }^{\circledR}$ achieved a mean ventricular dilation of $3.03 \mathrm{~cm}^{2}(S D=0.77)$ (Fig. 2; Fig. 3b, ventricular re-expansion after ASD addition).

Symptomatic outcomes were analyzed in relation to changes in ventricular size on imaging. Specifically, 10 patients $(\simeq 30 \%)$ experienced some degree of isolated ventricular dilation after treatment, and 10/32 $(\simeq 30 \%)$ noticed an improvement of headaches, confusion, vision, and/or other neurologic complaints. On the other hand, only 9 of 32 patients had evidence of both radiologic and symptomatic improvement $(28 \%)$.

\section{Discussion}

The introduction of ball-and-spring valves by Nulsen and Spitz in 1949 revolutionized the treatment of hydrocephalus, making conditions with raised ICP surgically treatable ${ }^{16}$. Although IIH has been treated with shunting for decades, a shift from lumbar to ventriculo-peritoneal shunting has occurred in recent years, mainly thanks to the higher precision allowed by navigation systems. Concurrently, other complications have arisen in patients with CSF diversion. In particular, shunt "overdrainage" has been recognized as one of the most severe consequences of supra-physiologic CSF diversion in VPS. This can lead to small ventricles on imaging, postural headaches and slow refill of the valve reservoir, as well as other neurologic symptoms ${ }^{12}$. VC can result in Slit-Ventricle Syndrome (SVS), an entity that presents with nausea in the adult population, and premature fusion of cranial sutures with abnormal fibrous tissue and development of secondary craniosynostoses in children. These findings, although frequent among patients with VPS, have rarely been classified into a well-defined clinical syndrome in adult patients, and the limited available evidence for IIH significantly undermines the efficacy of current treatments.

In this study, we aimed to investigate retrospectively in a large cohort of IIH patients treated with ventriculo-peritoneal shunts, the risk factors, clinical and imaging presentation, and treatment outcomes of this therapeutic approach. $\mathrm{IHH}$ patients have in fact several characteristics that make them prone to 
develop VC upon shunting, among which the most prominent are the slit-like appearance and small volume of ventricles at baseline $e^{9,10}$

Further, raised ICP can determine a significant pressure gradient between the ventricles and the peritoneum, increasing the rate of CSF drainage ${ }^{17,18}$, while the higher distance between the proximal and distal catheters ends in adults makes these devices even more prone to overdrainage than in children.

\section{Risk factors of Ventricular Collapse and their Clinical Importance}

Several demographic, radiologic, and vascular risk factors with a role in the development of VC were analyzed. In particular, the use of uni- and multivariate analyses revealed that subjects with smaller ventricles at baseline are more prone to undergo uni- or bilateral VC. This finding, although not surprising from a geometric perspective, is relevant in two ways: first, it raises the hypothesis that abnormally small ventricles result from parenchymal turgor, that also provides a greater force for collapse. Secondly, it suggests the potential use of ventricular size on baseline imaging as a surrogate clinical marker to individuate those patients at risk of developing $\mathrm{VC}$ upon shunting.

A possible explanation to the different responses to VPS seen in our cohort could be found in brain turgor $^{19}$, parenchymal compliance, and the movement of extra- and intracellular water. In support of this hypothesis, the smaller volume of lateral ventricles at baseline could be interpreted as a sign of increased parenchymal turgor, reflecting a stronger predisposition to collapse in patients with $\mathrm{IIH}$ and reduced ventricular volume after VPS. In addition, patients with smaller ventricles at baseline experienced a significantly larger decrease in size after shunting, compared to patent ventricles. Patients with VC were found to have a larger decrease in total ventricle area after shunting despite having smaller ventricles preprocedural (Table 4).

Furthermore, compliance appears to be driven mainly by the displacement and movement of intracranial blood volume, and in particular by its venous component ${ }^{9,14,15,19}$. Similarly, venous congestion and collapse have been linked to cerebral turgor and distensibility by a variety of studies ${ }^{9,14,19}$, and appear to be involved in the pathogenesis of $\mathrm{IH}$ and SVS. Consistently with this hypothesis, the ventricular size at baseline may be interpreted as a sign of parenchymal turgor, where smaller ventricles correspond to a larger parenchymal elastic modulus and therefore a higher tendency to collapse upon shunting. VPS in fact, by decreasing the ventricular CSF pressure, reduces the vector counteracting parenchymal turgor and promotes collapse. Further, the lower ICP determined by shunt overdrainage has an indirect effect on cranial veins distensibility, making them more prone to collapse in the supine position, and distended when the patient is standing. The contribution of the venous system therefore becomes an important actor in VC pathogenesis and maintenance, both for its effect on craniocerebral compliance and for the bidirectional effects on CSF dynamics ${ }^{9,20-24}$. While shunting induces lower pressures in the CSF compartment, venous congestion and sinus/venous stenosis also impact brain distensibility and 
intracranial volume, potentially modulating the response to treatment and the instauration of a vicious cycle of collapse and re-expansion. Finally, a negative but important finding is represented by the similar distribution of stenotic venous sinuses recorded in the two cohorts, suggesting that the role played by these factors is likely less relevant than previously thought, and that future studies with more sensitive measures are needed to assess their true contribution to the etiopathogenesis of IIH and VC.

\section{Effect of Valve Type and Setting on Ventricular Collapse}

Low-pressure valves and shunt overdrainage have been identified as two of the most important risk factors of VC and SVS ${ }^{13,24-31}$. For this reason, high OP and programmable valves should be useful in treatment along with the addition of antigravity or antisiphon devices. Programmable valves were used in all subjects, while six patients also received an integrated high-resistance surge-induced alternate high resistance pathway SiphonGuard ${ }^{\circledR}$ ).

Although the majority of the valves (64 subjects) were set to a high resistance level of 6 (corresponding to an OP of $18 \mathrm{cmH}_{2} \mathrm{O}$ ) 28 patients ( $43 \%$ of the total) still developed VC. On the other hand, seven patients $(7 / 73)$ received a programmable valve with SiphonGuard ${ }^{\circledR}$, and only one experienced VC. These findings suggest that despite the use of programmable valves alone, even at high OP, the occurrence of shunt overdrainage is still a frequent complication. Even high-resistance settings could therefore be insufficient for preventing VC, and the addition of an ASD may improve the flow dynamics and symptomatology. However, our evidence suggests that the ability to increase OP could also reduce the risk of VC and maintain the ventricles dilated in the period after VPS insertion. Although this could cause the persistence of some manifestations of $\mathrm{IIH}$, avoiding the onset of $\mathrm{VC}$ might be essential to maintain a normal CSF circulation in the ventricular-subarachnoid, interstitial and transependymal spaces. Furthermore, this could also prevent the onset of a cycle of collapse and re-expansion, difficult to halt once collapse has developed.

\section{Therapeutic Strategies to Reverse Ventricular Collapse}

VC is a challenging complication of VPS, usually addressed with an empirical approach, depending on the underlying cause. In some instances, ventricular catheter position is modified or catheters added to drain residual areas of fluid. Unfortunately, this does not address the problem of overdrainage and often results in subsequent collapses. Further, craniospinal disproportion can result in slit and collapsed ventricles and may be best treated with cranial expansion. However, these solutions are not often feasible or first choice of treatment. Valve adjustment appears to be an effective first-line measure in patients with VC, and raising the OP to $21 \mathrm{cmH}_{2} \mathrm{O}$ or higher achieves radiologic or symptomatic relief in $50 \%$ of our cases. In case of failure of this approach, postural overdrainage can be limited by adding an ASD (in our case) to the shunt in use. Although the numbers are small in this series, all the VC patients that were implanted with an ASD after refractory VC experienced complete radiologic and symptomatic resolution. Despite the additional cost and mechanical complexity the use of this shunt adjunct may be justified upfront in all $\mathrm{IIH}$, and strong support to this solution can be found in the literature $\mathrm{r}^{32-34}$. 


\section{Association of Symptoms and Ventricular Size after Collapse}

In this study we found that shunting is usually effective in decreasing headaches and papilledema following the procedure, but these effects can disappear after about six months, both in VC and non-VC subjects (Table 2). Noticeably, unless shunt blockage has occurred, papilledema and ICP remain resolved in patients with the recurrent headaches of $\mathrm{IH}$, suggesting that other underlying factors might explain shunt-related headaches (Supplementary Table 1).

In our patients that improved after VC only a fraction experienced both symptomatic and radiologic improvement (both headaches relief and ventricular re-expansion). While 10 subjects out of 32 had significantly larger ventricles post-VC resolution on CT/MRI, and 10/32 reported symptomatic improvement, only 9 patients were observed to have both symptomatic and anatomical resolution. It seems clear that the headaches are not directly based on VC and are likely multifactorial. While reexpanding collapsed ventricles may be beneficial from the standpoint of reducing the risk of shunt failure, they are not always associated with the resolution of multifactorial headaches.

\section{Prevention and Treatment of Ventricular Collapse}

VC is generally considered an elusive complication of VPS and its pathophysiologic understanding has frequently been framed in the context of SVS in pediatric patients. Nonetheless, the frequency and severity of $\mathrm{VC}$ in adult IIH patients deserves a better comprehension and a more extensive use of evidence-based treatments.

Within the appropriate clinical context, a small ventricular size on imaging (under $9 \mathrm{~cm}^{2}$ of total area) can be a useful indicator of likely VC. Such patients may be provided with a system using a higher OP and the addition of an ASD. Based on our series, VC could likely be prevented by the use of a surge-induced high resistance pathway protector (Siphonguard ${ }^{\circledR}$ ) or adjustable gravity device (ProSa ${ }^{\circledR}$ ) in the initial shunting of high-risk IIH patients.

Finally, once VC has developed, a number of measures should be taken to induce ventricular reexpansion. First, the valve OP should be raised to a higher resistance, greater than $20 \mathrm{cmH}_{2} \mathrm{O}$. This usually allows prompt ventricular re-expansion, despite sometimes resulting in recurrence of IIH "high-pressures" headache symptoms. If this measure fails, the addition of an ASD could reduce postural drainage in presence of symptoms of shunt overdrainage, and improve VC.

\section{Multivariate Linear Regression Models for Predicting Ventricular Collapse}

The first multiple regression grouped a number of factors that have been related to the presentation and perhaps etiology of $\mathrm{IHH}$. As a such they may be thought to play a role in the risk of ventricular collapse. Despite their strong association with $\mathrm{IH}$, papilledema and increased $\mathrm{BMI}$ at presentation, and the 
presence or absence of bilateral transverse sinus stenosis all did not show a significant relationship with development of VC. This may be due in part to the high prevalence of some of these factors in the group and the limited information conveyed by the measurements used (e.g. binomial separation into stenotic/non-stenotic sinuses, subjective classification of papilledema). The significant prediction of ventricular collapse which was observed was largely based on presenting ventricular size. Whether especially small ventricles represent a more severe case of $\mathrm{IIH}$, or just a smaller starting point is not clear. However, an association of small ventricles with increased shrinkage after shunting suggests it was not just the smaller starting point but also a greater driving force that determined collapse.

In the second model, a combination of post-shunting variables (symptoms and area measures) also showed significant association with development of collapse after shunting. As expected, greater decreases in size was associated with VC. However, importantly, the appearance of headache symptoms at six months appeared associated with $\mathrm{VC}$ risk and was also found more frequently in patients with VC in the univariate analysis.

\section{Limitations}

Our attempt to study the risk factors of $\mathrm{VC}$ in $\mathrm{IIH}$ and explain their role in determining shunt- and VCrelated headaches is not without limitations. First, as a retrospective series the design has certain limitations in assessing the role of the main demographic variables on $\mathrm{IIH}$ and $\mathrm{VC}$ pathogenesis, and future prospective investigation will therefore expand on similar end-points to validate the findings. Furthermore, the intervals between CT/MRI scans and other instrumental analyses were variable, and ventricular size was estimated with $2 \mathrm{D}$ image-segmentation, not perfectly reproducing the volume of lateral and third ventricles. Nonetheless, we considered this a valid approximation of the clinical setting and a first approximation to developing a model for ventricular collapse and treatment. Clearly, a prospective application of multivariate models along with quantitative imaging parameters of ventricular size in the clinical setting, with the aim of better tracking the anatomical response to variable shunt drainage, will allow better prediction and prevention of $\mathrm{VC}$ and understanding of the relationships between pathophysiology, shunt function and symptoms.

\section{Summary And Conclusion}

Ventricular collapse, often unilateral, was observed in roughly a third of patients after initial shunting, and was associated - together with ventricular area - with worsening symptoms of $\mathrm{IIH}$ (primarily headaches). This occurred even with a high differential pressure settings of $180 \mathrm{~mm}$ water.

High opening pressures and controlled positional drainage are important factors in the treatment of IIH. The observed collapse can be treated by further increasing valve opening pressures alone or with addition of a form of antisiphon device, with resulting re-expanded ventricles and/or reduces symptoms. Although numbers here are limited, as shown by others, the addition of a positional device is useful in prevention and treatment of ventricular collapse, and is therefore recommended. This is especially true in IIH patients with smaller ventricles, where collapse rates are higher and symptoms redevelop more often. Interestingly, 
bilateral transverse sinus stenosis and/or a high BMI were not associated with higher rates of collapse, thus questioning their direct roles in VC risk after shunting. While successful ventricular re-expansion and/or symptoms resolution were achieved in $87 \%$ of patients overall, using valve adjustments and additions, these benefits occurred concomitantly in only $~ 30 \%$ of the cases, supporting the idea of a multifactorial etiology for IIH headaches.

In conclusion, our data, with the help of a quantifiable imaging measure, show that CSF drainage and valve resistance settings contribute significantly to a relatively high rate of $\mathrm{VC}$ symptomatology and clinical progression. While presenting $\mathrm{IH}$ factors, with exception of presenting ventricular size, did not play a role in the frequency of collapse, ventricular collapse was related to a greater ventricular size response to shunting and to the presence of headaches at 6 months. Importantly, while VC could be treated with increased opening pressure and gravity regulation, the ventricles volume and symptomatic relief were often not associated. This finding further highlights the importance of CSF overdrainage rather than mere ventricular size - in the pathogenesis and symptomatology of $\mathrm{VC}$, and suggests a potential explanation for shunt-associated complications.

\section{Abbreviations}

VC

ventricular collapse

$\mathrm{IIH}$

Idiopathic Intracranial Hypertension

CSF

Cerebrospinal Fluid

VPS

Ventriculoperitoneal Shunt

ASD

Anti-Siphon Device

OP

Opening Pressure

LP

lumbar puncture

\section{Declarations}

\section{Ethics approval and consent to participate}

Not applicable.

\section{Consent for publication}

Not applicable. 
Availability of data and materials

All data and materials included in these studies will be freely shared with any interested party. The data that support the findings of this study are available from the authors.

\section{Funding}

We would like to acknowledge The Berry-Brem Professorship in Neurosurgery whose generous funding made this work possible.

\section{Authors' Contributions}

RS, SM, SH, MM, NLG and LM acquired, analyzed, interpreted the data, and wrote the manuscript. RS, MM, AM and MGL designed the experiments, analyzed and interpreted the data, and wrote the manuscript. All authors approved the final version of the manuscript.

\section{Acknowledgments}

We thank The Johns Hopkins Center for CSF Disorders for the support and guidance throughout the entire project.

\section{Ethics Approval and Consent to Participate}

Johns Hopkins University Institutional Review Board.

\section{Consent for Publication}

Not applicable.

\section{References}

1. Friedman, D. I., Liu, G. T. \& Digre, K. B. Revised diagnostic criteria for the pseudotumor cerebri syndrome in adults and children. Neurology 81, 1159-1165 (2013).

2. Corbett, J. J. et al. Visual loss in pseudotumor cerebri: follow-up of 57 patients from five to 41 years and a profile of 14 patients with permanent severe visual loss. Archives of neurology 39, 461-474 (1982).

3. Rosenberg, M. et al. Cerebrospinal fluid diversion procedures in pseudotumor cerebri. Neurology 43, 1071-1071 (1993).

4. Karahalios, D. G., Rekate, H. L., Khayata, M. H. \& Apostolides, P. J. Elevated intracranial venous pressure as a universal mechanism in pseudotumor cerebri of varying etiologies. Neurology 46, 198202 (1996).

5. Fonseca, P. L., Rigamonti, D., Miller, N. R. \& Subramanian, P. S. Visual outcomes of surgical intervention for pseudotumour cerebri: optic nerve sheath fenestration versus cerebrospinal fluid 
diversion. British Journal of Ophthalmology 98, 1360-1363 (2014).

6. Burgett, R. A., Purvin, V. A. \& Kawasaki, A. Lumboperitoneal shunting for pseudotumor cerebri. Neurology 49, 734-739 (1997).

7. Garton HJ Cerebrospinal fluid diversion procedures. Journal of neuro-ophthalmology 24, 146-155 (2004).

8. Sinclair, A. J. et al. Is cerebrospinal fluid shunting in idiopathic intracranial hypertension worthwhile? A 10-year review. Cephalalgia 31, 1627-1633 (2011).

9. Bateman, G. A. Hypertensive slit ventricle syndrome: pseudotumor cerebri with a malfunctioning shunt?: Report of 3 cases. Journal of neurosurgery 119, 1503-1510 (2013).

10. Jacobson, D. M., Karanjia, P. N., Olson, K. A. \& Warner, J. J. Computed tomography ventricular size has no predictive value in diagnosing pseudotumor cerebri. Neurology 40, 1454-1454 (1990).

11. AHLSKOG, J. E. \& O'NEILL, B. P. Pseudotumor cerebri. Annals of Internal Medicine 97, 249-256 (1982).

12. Hyde-Rowan, M. D., Rekate, H. L. \& Nulsen, F. E. Reexpansion of previously collapsed ventricles: the slit ventricle syndrome. Journal of Neurosurgery 56, 536-539 (1982).

13. Chernov, M. F., Kamikawa, S., Yamane, F., Ishihara, S. \& Hori, T. Neurofiberscope-guided management of slit-ventricle syndrome due to shunt placement. Journal of Neurosurgery: Pediatrics 102, 260-267 (2005).

14. Rekate, H. L. Shunt-related headaches: the slit ventricle syndromes. Child's Nervous System 24, 423430 (2008).

15. Rekate HL, Kranz D. in Seminars in pediatric neurology. 27-30 (Elsevier).

16. Nulsen F. in Surg Forum. 399-403.

17. Pudenz, R. H. \& Foltz, E. L. Hydrocephalus: overdrainage by ventricular shunts. A review and recommendations. Surgical neurology 35, 200-212 (1991).

18. Aschoff, A. et al. Overdrainage and shunt technology. Child's Nervous System 11, 193-202 (1995).

19. Rekate, H. L. Brain turgor (Kb): intrinsic property of the brain to resist distortion. Pediatric neurosurgery 18, 257-262 (1992).

20. Dwyer, C. M., Prelog, K. \& Owler, B. K. The role of venous sinus outflow obstruction in pediatric idiopathic intracranial hypertension. Journal of Neurosurgery: Pediatrics 11, 144-149 (2013).

21. Higgins, J., Cousins, C., Owler, B., Sarkies, N. \& Pickard, J. Idiopathic intracranial hypertension: 12 cases treated by venous sinus stenting. Journal of Neurology, Neurosurgery \& Psychiatry 74, 16621666 (2003).

22. Puffer, R. C., Mustafa, W. \& Lanzino, G. Venous sinus stenting for idiopathic intracranial hypertension: a review of the literature. Journal of neurointerventional surgery 5, 483-486 (2013).

23. Epstein, F., Lapras, C. \& Wisoff, J. H. 'Slit-ventricle syndrome': etiology and treatment. Pediatric Neurosurgery 14, 5-10 (1988).

24. Olson, S. The problematic slit ventricle syndrome. Pediatric neurosurgery 40, 264-269 (2004). 
25. Kan, P., Walker, M. L., Drake, J. M. \& Kestle, J. R. Predicting slitlike ventricles in children on the basis of baseline characteristics at the time of shunt insertion. Journal of Neurosurgery: Pediatrics 106, 347-349 (2007).

26. Albright, A. L. \& Tyler-Kabara, E. Slit-ventricle syndrome secondary to shunt-induced suture ossification. Neurosurgery 48, 764-770 (2001).

27. Walker, M. L., Fried, A. \& Petronio, J. Diagnosis and treatment of the slit ventricle syndrome. Neurosurgery clinics of North America 4, 707-714 (1993).

28. Serlo, W., Saukkonen, A.-L., Heikkinen, E. \& Von Wendt, L. The incidence and management of the slit ventricle syndrome. Acta neurochirurgica 99, 113-116 (1989).

29. Liniger, P., Marchand, S. \& Kaiser, G. Flow control versus antisiphon valves: late results concerning slit ventricles and slit-ventricle syndrome. European Journal of Pediatric Surgery 13, 3-6 (2003).

30. Iglesias, S. et al. Surgical outcome of the shunt: 15 -year experience in a single institution. Child's Nervous System 32, 2377-2385 (2016).

31. Di Rocco, C., Massimi, L. \& Tamburrini, G. Shunts vs endoscopic third ventriculostomy in infants: are there different types and/or rates of complications? Child's Nervous System 22, 1573-1589 (2006).

32. Koueik, J. et al. A 12-year single-center retrospective analysis of antisiphon devices to prevent proximal ventricular shunt obstruction for hydrocephalus. Journal of Neurosurgery: Pediatrics 24, 642-651 (2019).

33. Gruber, R. W. \& Roehrig, B. Prevention of ventricular catheter obstruction and slit ventricle syndrome by the prophylactic use of the Integra antisiphon device in shunt therapy for pediatric hypertensive hydrocephalus: a 25-year follow-up study. Journal of Neurosurgery: Pediatrics 5, 4-16 (2010).

34. Portnoy, H. D., Schulte, R. R., Fox, J. L., Croissant, P. D. \& Tripp, L. Anti-siphon and reversible occlusion valves for shunting in hydrocephalus and preventing post-shunt subdural hematomas. Journal of neurosurgery 38, 729-738 (1973).

\section{Figures}


a) Catheter Tip Scan

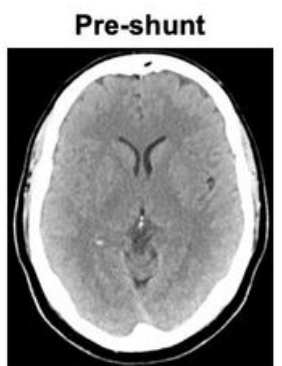

c)

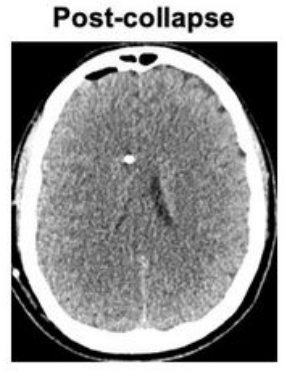

b)

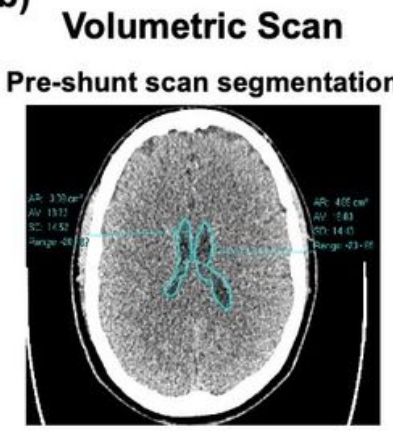

d)



Ie)



Ig)

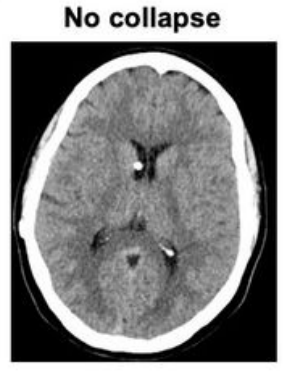

f)

Volumetric Scan

Pre-shunt scan segmentation

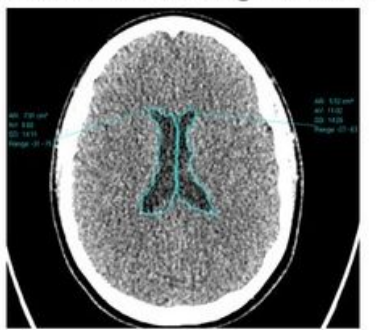

h)

Post-shunt scan segmentation



Figure 1

Methods of image segmentation. Fig. 1a-c-e-g) pre- and post-VPS assessment of ventricular patency. In post-VPS scans patency and collapse are evaluated at the level of the catheter tip. Fig. 1b-d-f-h) ventricular area is calculated with manual scan segmentation at the point of maximum width in patent and collapse ventricles.

a) Catheter Tip Scan

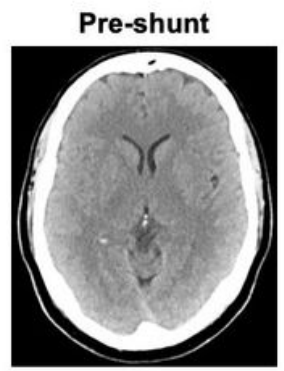

c)



b)
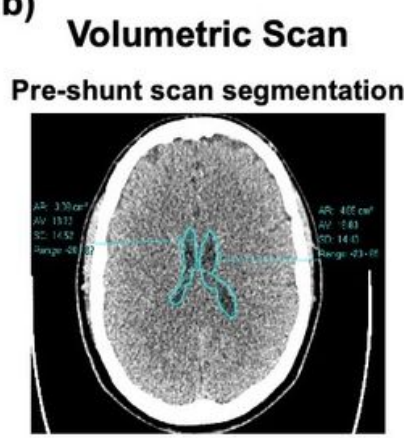

d)

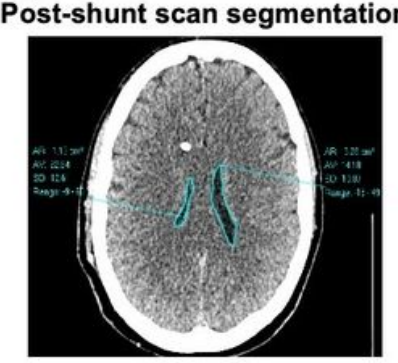

Ie)



Ig)

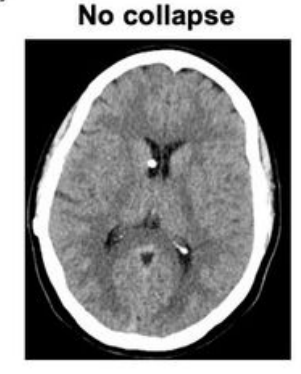

f)

Volumetric Scan

Pre-shunt scan segmentation

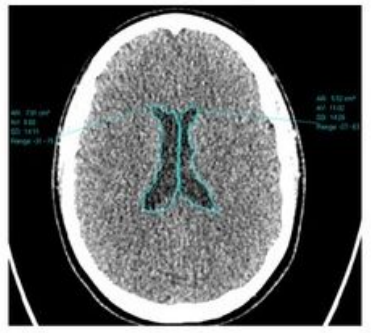

h)

Post-shunt scan segmentation

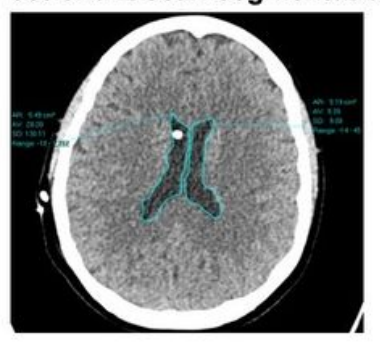


Figure 1

Methods of image segmentation. Fig. 1a-c-e-g) pre- and post-VPS assessment of ventricular patency. In post-VPS scans patency and collapse are evaluated at the level of the catheter tip. Fig. 1b-d-f-h) ventricular area is calculated with manual scan segmentation at the point of maximum width in patent and collapse ventricles.

a)
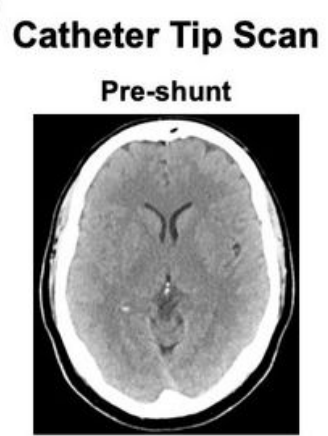

c)



b)

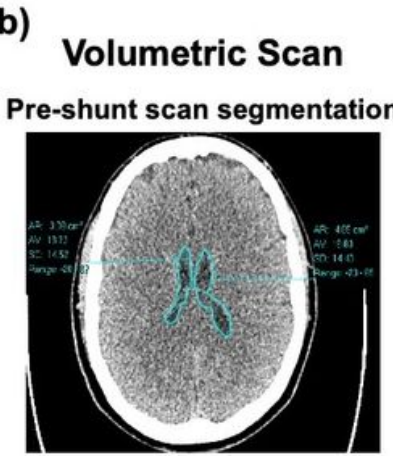

d)

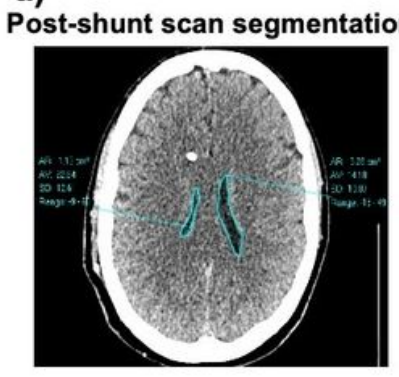



Ig)



f) Volumetric Scan

Pre-shunt scan segmentation

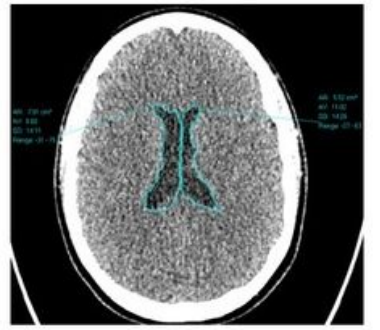

h)

Post-shunt scan segmentation



\section{Figure 1}

Methods of image segmentation. Fig. 1a-c-e-g) pre- and post-VPS assessment of ventricular patency. In post-VPS scans patency and collapse are evaluated at the level of the catheter tip. Fig. 1b-d-f-h) ventricular area is calculated with manual scan segmentation at the point of maximum width in patent and collapse ventricles. 

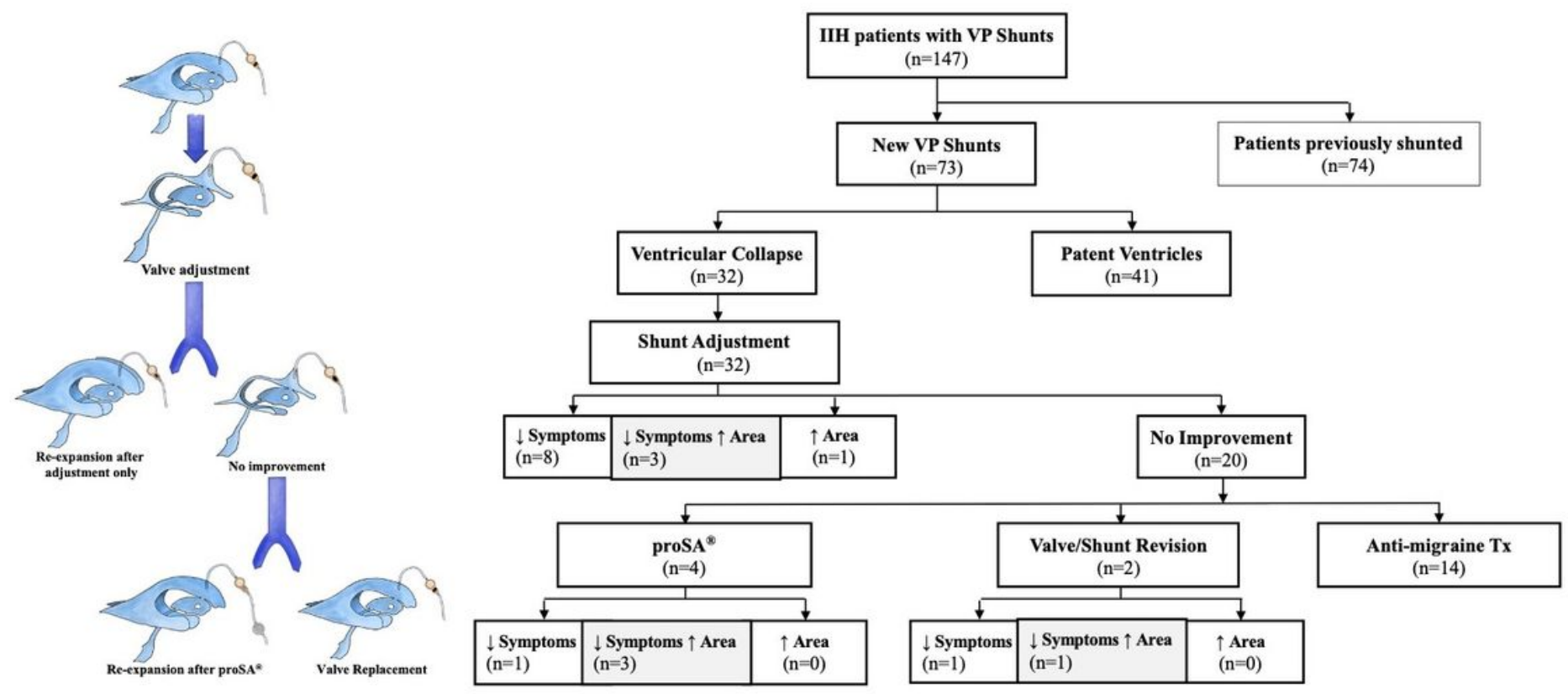

Figure 2

Study workflow and schematic of ventricular collapse timeline.
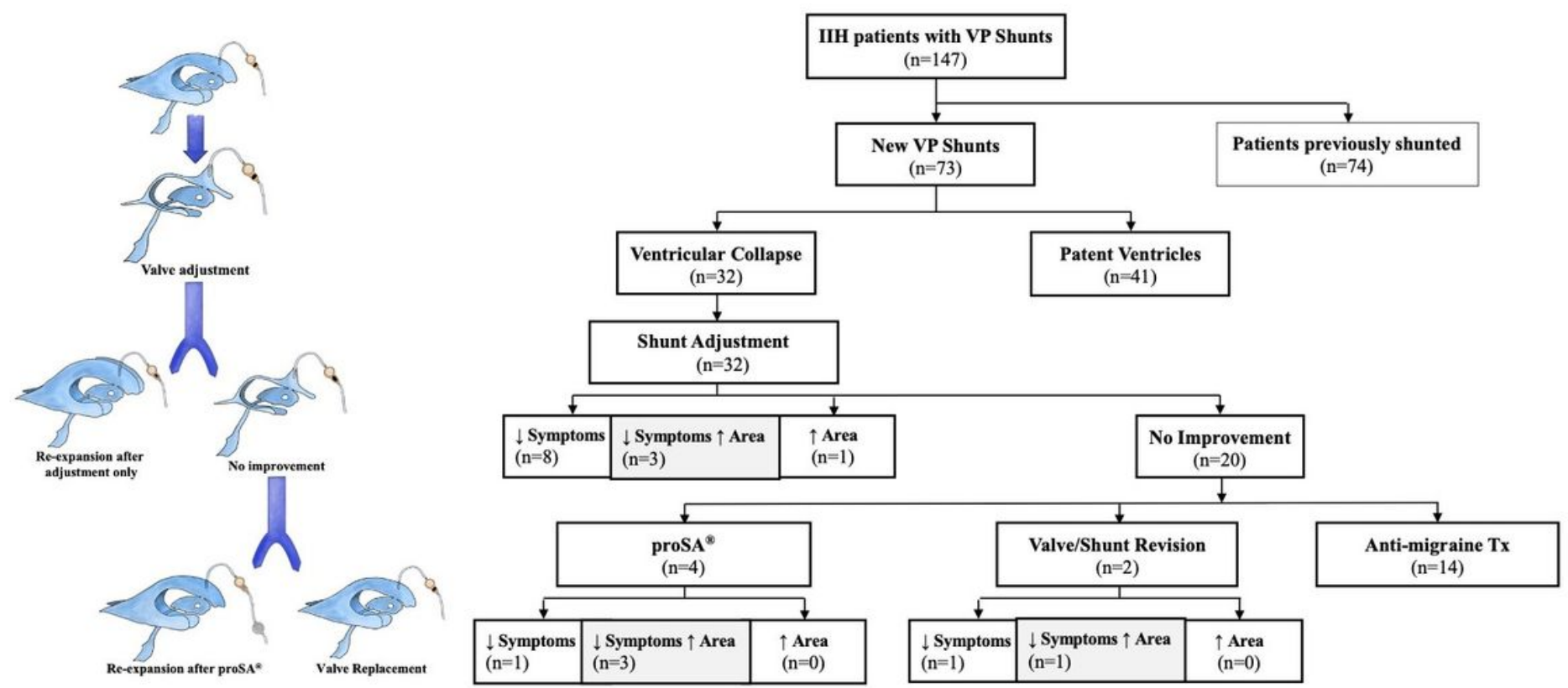

Figure 2

Study workflow and schematic of ventricular collapse timeline. 



Figure 2

Study workflow and schematic of ventricular collapse timeline. 
a)

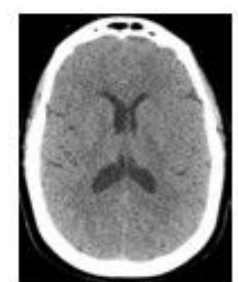

Baseline


Baseline



震

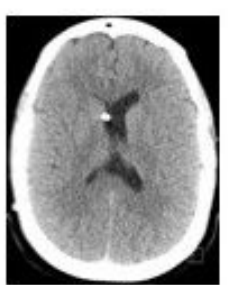

8

COLLAPSE

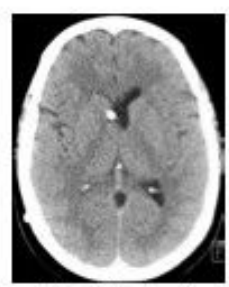

Valve Adjustment

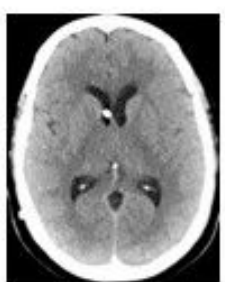

Re-Expansion 응

b)

c)

Overall Ventricular Area Change



\section{Figure 3}

Representative cases of VC treatment. A) Example of ventricular re-expansion after valve adjustment in unilateral VC; $b$ ) the addition of a proSA $\AA^{A S D}$ achieved ventricular re-expansion and symptomatic improvement in a subject that did not respond to valve adjustment; c) average change in ventricular area (with $95 \% \mathrm{Cl}$ ) after shunting, post-VC and post-treatment in subjects diagnosed with VC. 
a)



Baseline


Baseline

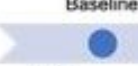

震



8

COLLAPSE

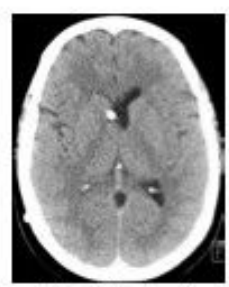

Valve Adjustment

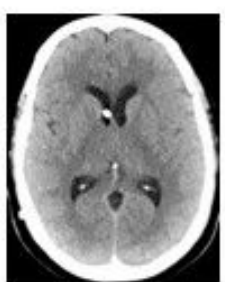

Re-Expansion 응

b)

c)

Overall Ventricular Area Change

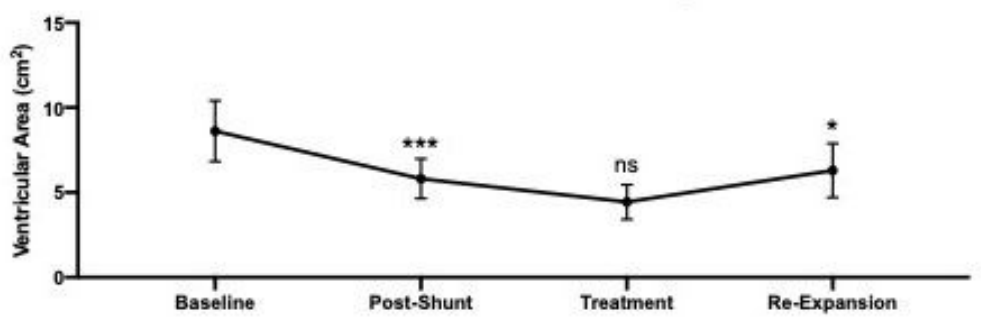

\section{Figure 3}

Representative cases of VC treatment. A) Example of ventricular re-expansion after valve adjustment in unilateral VC; $b$ ) the addition of a proSA $\AA^{A S D}$ achieved ventricular re-expansion and symptomatic improvement in a subject that did not respond to valve adjustment; c) average change in ventricular area (with $95 \% \mathrm{Cl}$ ) after shunting, post-VC and post-treatment in subjects diagnosed with VC. 
a)

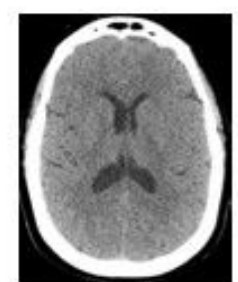

Baseline
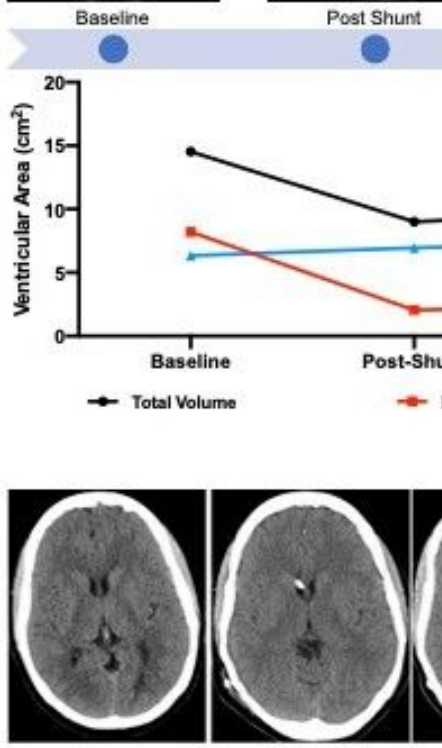

Baseline

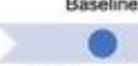

震



8

COLLAPSE



Valve Adjustment



Re-Expansion 응

b)

c)

Overall Ventricular Area Change



\section{Figure 3}

Representative cases of VC treatment. A) Example of ventricular re-expansion after valve adjustment in unilateral VC; $b$ ) the addition of a proSA $\AA^{A S D}$ achieved ventricular re-expansion and symptomatic improvement in a subject that did not respond to valve adjustment; c) average change in ventricular area (with $95 \% \mathrm{Cl}$ ) after shunting, post-VC and post-treatment in subjects diagnosed with VC. 


\section{Supplementary Files}

This is a list of supplementary files associated with this preprint. Click to download.

- Slide4.jpeg

- Slide4.jpeg

- Slide4.jpeg

- Slide5.jpeg

- Slide5.jpeg

- Slide5.jpeg

- Slide6.jpeg

- Slide6.jpeg

- Slide6.jpeg

- SupplementaryTable1.docx

- SupplementaryTable1.docx

- SupplementaryTable1.docx 